\title{
Cross-scale risk perception: differences between tribal leaders and resource managers in Arctic Alaska
}

\author{
Berill Blair $^{1}$ and Gary P. Kofinas ${ }^{2}$
}

\begin{abstract}
Communities of Alaska's North Slope are affected by concurrent, rapid changes due to climate change and industrial activities. Because these impacts are expected to shape community planning agendas into the foreseeable future, increased attention has been paid to decision-making processes that support adaptation. The planning and development decisions that shape adaptation outcomes in North Slope communities take place within complex institutional and policy processes. At the same time, the resilience of rural Alaska communities is closely tied to the extent their interests and local-level priorities are reflected in national- and regionallevel decisions on resources that support local livelihoods. For this reason it is important to survey which adaptive responses are of high priority and what are the risks to adaptation at the community level. Given the nested nature of institutions in the region, comparing perceptions across scales can provide insight into potential areas of agreement and difference. To assess these differences, we surveyed North Slope Iñupiat tribal leaders and Alaska State and U.S. federal resource management professionals about perceived risks to North Slope community sustainability. Results showed shared areas of understanding about the extent of impacts from certain changes. However, there were marked differences in risk priorities, in the evaluations of local capacity to treat risks, and community resilience. Our findings suggest that although there are effective channels of communication to exchange observations and understandings regarding land use and cover changes, the views on risk and resilience held by key actors correlate with their role in and proximity to the social-ecological system under examination. By evaluating scale-specific risk priorities and the resources already in place to respond to change, decision makers can better leverage existing resources and adaptive capacities.
\end{abstract}

Key Words: adaptation; Arctic; community development; institutional fit; risk perception; sustainability

\section{INTRODUCTION}

Risks, institutions, and the capacity to adapt

Mitigating threats to ecosystem function and community sustainability in villages of the North Slope (NS) of Alaska (Fig. 1) hinges to a great extent on how people define risks (Blair et al. 2014). Only acknowledged risks can be addressed. But how risks are perceived is tied to bias, attitudes, worldviews, and preferences (Fischhoff et al. 1978, Douglas and Wildavsky 1982, Lichtenstein and Slovic 2006, Kahan et al. 2012). Perceived risks differ from calculated risks measured with quantified assessments (Aven 2016), and come with biases that ultimately shape adaptation outcomes (Adger et al. 2009). As repeatedly found with case study research, in rapidly changing social-ecological systems it is key that policies that govern risks encourage effective environmental stewardship and responsiveness to local-level priorities (Chapin et al. 2009, Glaser et al. 2010, McMillen et al. 2017). But in the assessment of risks in the NS region, significant challenges arise in setting such priorities because of the complex political hierarchy that governs how decisions are made. In Arctic Alaska, borough, state, and federal-level institutions are superimposed over traditional tribal governments, and the regulations governing resources are debated across scales, institutions, and with a plurality of values and knowledge systems. The effectiveness of institutions is a function of fit with the biophysical and social domains in which they operate (e.g., Young 2002, Folke et al. 2007). An understanding of fit is necessary because carefully devised solutions that can address key issues must be based on thorough knowledge of the essential features of a problem (Young 2013). For Indigenous communities, institutional fit with cultural norms, traditional knowledge, and contemporary social processes is also crucial (Berkes 1999, Meek et al. 2011).
Fig. 1. Study area. Villages of the North Slope Borough, Alaska.

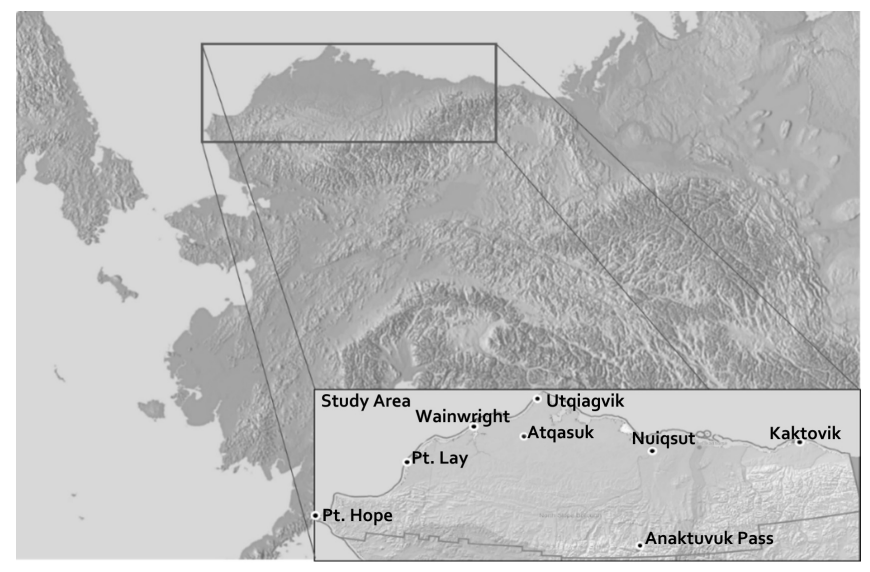

Successful adaptation to rapid, complex social-ecological change also demands special attention to local-level adaptation priorities (Hovelsrud et al. 2010, Ford et al. 2016). In the absence of these considerations, management conflicts and distrust can arise among key actors, as exemplified in several cases of Arctic resource management. Among the best known are events around differing perceptions by Iñupiat and scientists on the abundance of bowhead whales (Balaena mysticetus)in the mid-1970s (Huntington 2000), and similarly, differences between Arctic Indigenous peoples and resource managers in perceived abundance of barren ground caribou (Rangifer tarandus 
groenlandicus; Freeman 1989). And differences in perceived risks between Alaska Native leaders and scientists about the human health effects of Arctic environmental contamination resulted in the founding of the Alaska Native Science Commission in 1994 (Blair et al. 2014). These examples show how differing perceptions of risk can result in conflict, lack of compliance with rules and regulations, and in some cases, institutional innovation.

In Arctic Alaska, concurrent climate change and impacts from industrial development have resulted in significant land cover changes (Raynolds et al. 2014). On the one hand, industrial development is an opportunity for the strengthening of cash economies. On the other hand, development has to be balanced with environmental stewardship so that it does not conflict with subsistence activities and resources. For example, ongoing oil development has caused disturbance to some fish and wildlife species (Ahtuangaruak 2015). Similarly, impacts from climate change can cause deteriorations in food supply, infrastructure, water resources, ice sheets and coastal systems (Meredith et al. 2019). In other words, industrial development and climate change, as major drivers of change, shape adaptation planning in Arctic Alaska communities.

\section{Community sustainability in Arctic Alaska}

NS communities are inhabited primarily by Indigenous people, whose livelihoods are based on cash income and a subsistence harvesting based on enduring cultural traditions (Fig. 2; BurnSilver et al. 2016). Iñupiat have identified and navigated risks in their homelands for millennia. This long history of learning and adaptation has resulted in the accumulation of vast knowledge of the region's social-ecological system (Cochran et al. 2013). This expertise, however, is increasingly confronted by social-ecological conditions that are beyond their historical range. Communities have high stakes when it comes to the present and future well-being of the region. The emerging situation positions community leaders on the front lines of identifying risks to community sustainability and carefully safeguarding the building blocks that support community health and resilience.

There are 229 federally recognized tribes with their own tribal governments in Alaska. In 1971 the Alaska Native Claims Settlement Act endorsed land titles to 44 million acres of land to be managed by 12 for-profit Alaska Native regional corporations. The Act established property rights through shares of stocks in over 200 various Native regional and village corporations. The eight villages of the North Slope Borough are Alaska Native tribal entities and have their own tribal governments though their councils' authorities are limited to powers over people via membership, but not over place or territory, which is in the hands of corporate leadership (Kimmel 2014). Alaska Native residents of the NS are subject to rules and regulations at the borough, state, and federal level but at the same time, they are also represented by their tribal (village) council, the Iñupiat Community of the Arctic Slope, which is the regional tribal entity, and the Alaska Federation of Natives, the state-wide Native organization. Additionally, they have shares in their village-level for-profit corporation, and in the Arctic Slope Regional Corporation, which is the regional Native for-profit corporation. Health and social services are administered by the Arctic Slope Native Association as the region's nonprofit. These entities form a complex web of traditional and modern governance structures and institutions.
Fig. 2. Enduring cultural traditions of Alaska Iñupiat in the face of many social and ecological changes. (A) and (B) Iñupiaq drummers and dancers keep alive stories about the traditional way of life, (C) an Elder cutting caribou, (D) juxtaposition of traditional crafts and technology at an Utqiagivik store as atikłuich (hooded garments), beaded gloves, and fur hats are sold alongside electronics. Photographs by authors Blair and Kofinas and Gabriela Halas.

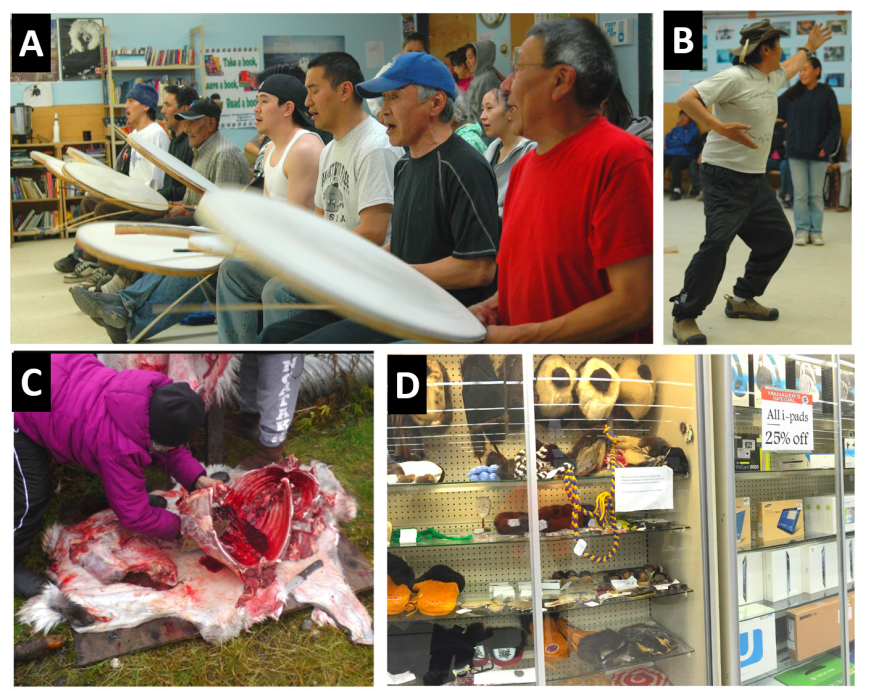

In past research about locally defined community sustainability in northern Alaska, local control over what happens to resources emerged as an important element (Kruse et al. 2004), mirroring findings at the Pan-Arctic level on the importance of "fate control" in community well-being (Larsen et al. 2010). In the Alaska context, six elements of sustainability were identified including the prevailing importance of homelands and resources, autonomy over decisions, healthy economies (both cash and subsistence), and cultural continuity (Kruse et al. 2004). In a report on research priorities for Northern Alaska, the Alaska Native Science Commission highlighted the value of local control and a focus on local perceptions (ANSC 2009). The Commission also noted an ongoing disconnect between the views of local communities and decision makers at higher levels, stating that local concerns were falling on deaf ears and NS communities felt marginalized. It concluded:

Individual and community sense of control over events
and activities that affect them should be evaluated in the
context of decision-making... Such an evaluation should
examine perceptions... to assess the degree to which local
concerns were addressed in subsequent decision-making
.. The degree to which community-based processes and
externally based processes are not compatible may help
illuminate causes of ineffective participation by
communities in various public forums (ANSC 2009:21).

The Commission's statement highlights the prominent role of decision-making contexts and local control in a community's sense of empowerment and well-being. The absence of 
collaboration or incongruence in risk perceptions among levels of government can lead to a lack of fit between institutions and the local social-ecological system. This may result for example in misguided bans on subsistence activities or incorrect quota considerations for the take of certain wildlife (Huntington 2000). An examination of the compatibility of local and nonlocal risk perceptions that may bear significance for important decisions about NS resources is the impetus for this research.

\section{Objectives and research questions}

In the implementation of effective adaptive strategies, local knowledge and control of the type, location, and timing of resources that best buffer against current and anticipated risks are critical (Fath et al. 2015, Lazrus 2015). Therefore an evaluation of how risks are perceived and prioritized by NS communities themselves, versus by higher level institutions, can reveal problem areas that may pose limits to positive change. The links between local perceptions of risk, local control over response strategies in the face of rapid change, and how they compare to the perceptions of professionals working at mesoand macro-levels of government is the focus of this paper.

We conducted a survey of individuals who represent formal governing bodies within the political hierarchy of Alaska's North Slope: tribal village councils, State of Alaska departments, and U.S. Federal bureaus. Borough-level entities were not included in this study because we wanted to bring prominence to a comparison of expert perspectives between the local traditional (tribal) governments and experts who do not reside in the NS region but advise influential governmental agencies on matters of high relevance to NS residents. Our survey captured views of NS risk issues across multiple scales, about uncertainty due to shifts in ecological and social trends, risks to sustainability, and perceptions about local capacities to manage risks. We focused on the following questions and methods of analysis:

1. To what extent do the two groups (local and nonlocal experts) share similar views about the speed and complexity of changes that impact the NS region's social-ecological system? We rely on a cross-impact analysis of uncertainties (Lindgren and Banhold 2009) to answer this question.

2. When it comes to risks that threaten NS community sustainability, and the capacity of communities to manage them, do the two groups evaluate and prioritize risks similarly? We rely on open ended and multiple choice survey questions, and exploratory factor analysis to answer this question.

We chose to survey tribal councils because they are the official village-level governmental body in the village-to-federal scale political hierarchy, and they represent Indigenous views of traditional lifeways and ancestral ties to the lands. There are eight NS village tribal councils and each council has seven elected councilors $(n=56)$.

\section{METHODS}

\section{Participants}

We developed a survey questionnaire and used a census survey approach to recruit participants for both the tribal council and for the state and federal resource manager group. We invited all eight NS tribal councils to participate. The councils of Utqiagivik (formerly Barrow), Anaktuvuk Pass, Nuiqsut, Point Hope, and Point Lay agreed to participate. Kaktovik, Atqasuk, and Wainwright were unable to partake in light of other competing projects that demanded the councils' attention. We successfully conducted onsite interview surveys in the five villages between January-March 2016, with $n=29$ of their 35 councilors (referred to herein as the "Tribal Council Group"). Among this group, two councilors (Nuiqsut) were past council members who filled in for two active councilors who were unavailable on the day of the interview. The six councilors not interviewed were away on travel or ill.

We identified eight representative entities, four state and four federal agencies, in charge of NS resource management. We defined resource management as activities related to the planning, development, or monitoring the NS region's natural resources. At these agencies we identified 90 employees within divisions responsible for NS resources. None resided in the NS region. Though not all these experts (herein referred to as the "Manager Group") make decisions about, or manage NS resources, their collective expertise informs policy makers in decision making. We disseminated surveys to all 90 experts. Our efforts resulted in $\mathrm{n}=$ 32 respondents (state $n=19$; federal $n=13$ ), composing a $35 \%$ response rate. Twenty surveys were completed in hard copy form and 12 via online surveys. Figure 3 shows the composition of the participant groups, including main areas of expertise for the Manager Group. The areas of expertise overlap for the majority of participants, who have competencies in multiple categories. The survey was administered in person to tribal councilors and detailed notes were taken on extra information offered by participants.

\section{The survey and analysis of data}

In the analyses of Likert-type question items, we report the central tendency of responses using median $(\mathrm{Mdn})$ values and the dispersion of responses using the interquartile range (IQR). These values represent what most respondents in each group believed (Mdn) and the extent of agreement (IQR). Because some councils requested that village-level results are not compared against one another, in all discussions we report results at the collective (regional) village-level only.

The survey administered to the Tribal Council Group began with six propositions to confirm that elements of community sustainability in Arctic Alaska identified by Kruse et al. (2004) and presented in Figure 4 are still applicable today (one of five levels of agreement allowed).

Perceptions of uncertainty: rapid, complex changes

To capture views about rapid changes and uncertainty, the survey used a dedicated set of questions adapted from Lindgren and Bandhold (2009). The questionnaire asked respondents to rate how rapid and complex the changes are that are impacting the NS region's social and ecological environments (Appendix 1). High scores on both the complexity and the speed of changes indicate greater difficulty in the planning environment, and greater uncertainty predicting future outcomes. The evaluations used a 7-point Likert scale format about perceptions of complexity (13 evaluative statements) and speed of changes (12 evaluative statements). The statements were evaluated by participants from 1 (completely disagree) to 7 (completely agree). Median results were charted along two axes, one for complexity, 
Fig. 3. Categorization of (a) Manager Group by expertise, (b) Manager Group by affiliation, and (c) Tribal Council Group by affiliation.

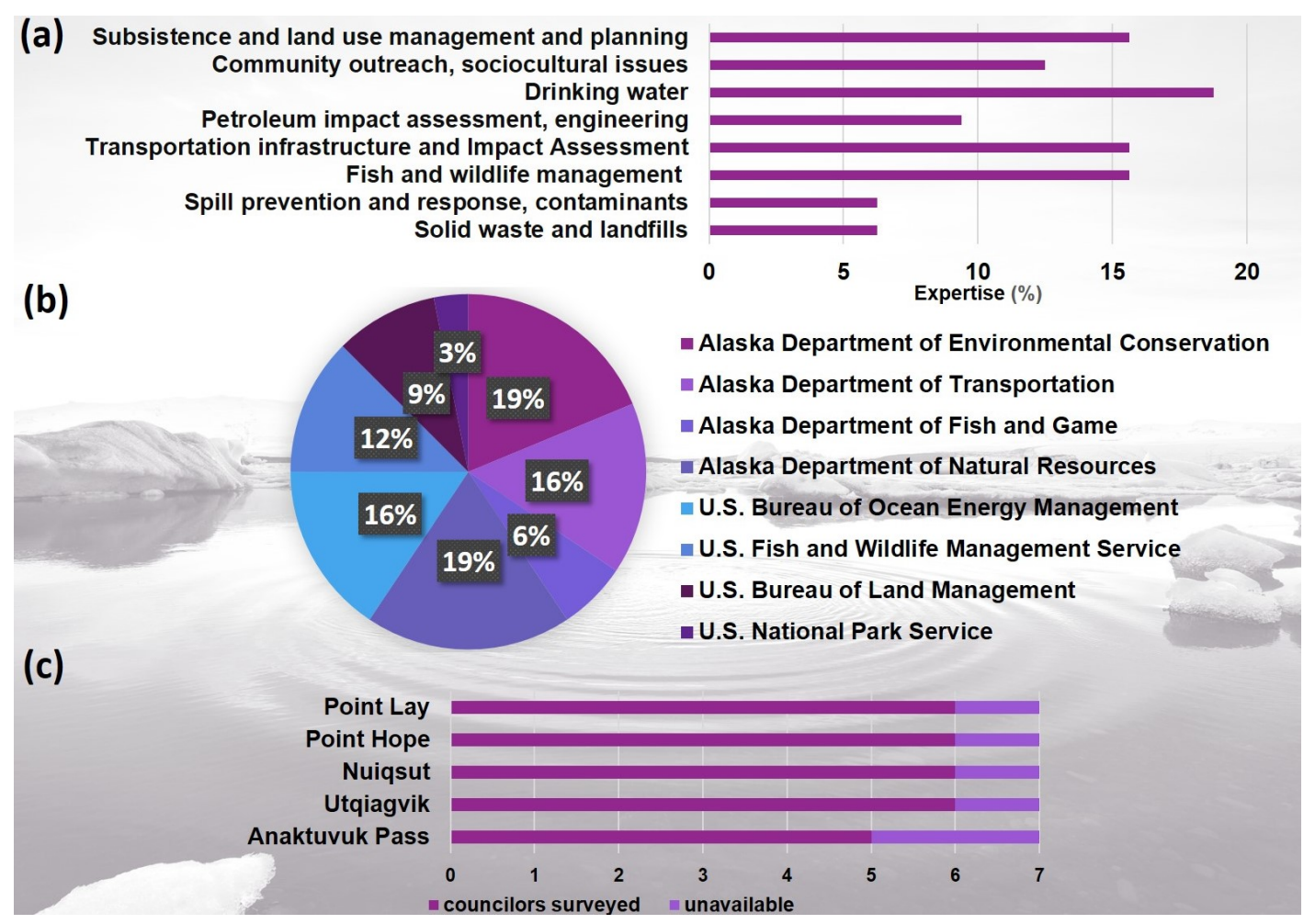

Fig. 4. Elements of Arctic Alaska community sustainability based on Kruse et al. (2004) and also confirmed in this study.

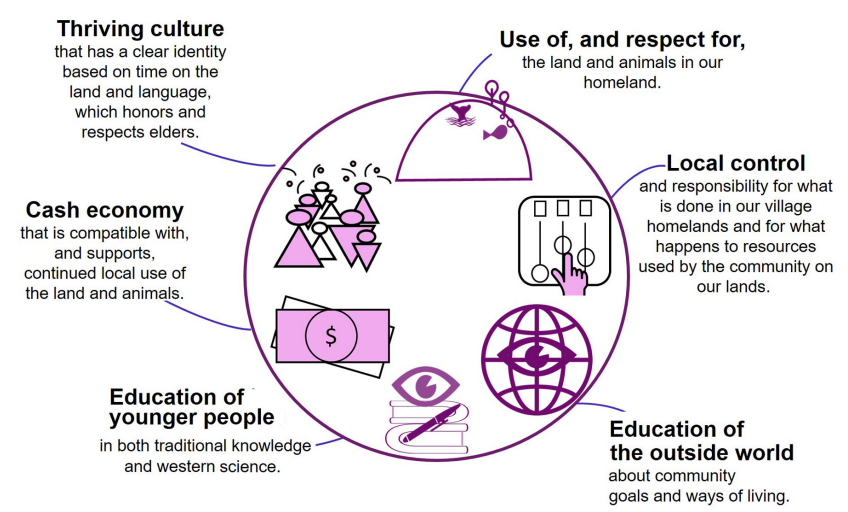

and another one for speed of changes. The resulting coordinates indicate the extent of uncertainty perceived in the NS decision environment by the two groups.

The 25 cross-impact statements were also subjected to exploratory factor analysis, observing guidelines after de Winter et al. (2009) for small sample sizes. Factor analysis helps to uncover latent constructs that explain group-specific trends; in our case it reveals how participants relate to the concepts of complexity and speed of change. The sampling adequacy and factorability of variables were tested using several methods (Appendix 2A), and found to be satisfactory (Appendix 2B). To extract factors, SPSS statistics software (IBMCorp. 20.0 edition, Armonk, New York, USA) was used. Correlated variables were connected in space like axes, each representing a factor. In order to optimize the axes to better fit the underlying data points, the program looks for ways to rotate them in space. We relied on principal axis factoring method because it makes no assumptions about data distribution, and an oblique rotation because it allows factors to be correlated (Baglin 2014). These approaches are commonly used in social sciences. The selection criteria for our final model is described in Appendix $2 \mathrm{~A}$.

Perceptions of risks

All questions on the survey asked respondents to think of the North Slope region as a whole, considering issues that impact all communities. To elicit perceptions of risks, the survey used a multipronged approach to identify the following:

1. Risk priorities: An open-ended question asked respondents to list the top five risks to community sustainability, to capture and compare risks high on each group's agenda. Responses were sorted using textual content into several distinct risk themes using a code system (Appendix 3) and analyzed using the software MAXQDA (v.12.0).

2. Risk dimensions: A list of 15 potential risk items were presented to respondents to see whether or not 
the same risks are evaluated similarly by the groups. These risk items were sourced using the following methods:

(i) Seven risk items were previously co-produced with residents of six Northern Alaska villages $(n=33)$ in a three-day regional workshop held in Utqiagivik in February 2015. These seven items were found to be of the highest priority by workshop participants.

(ii) Eight items related specifically to land cover change were collected from previous ethnographic research in the region (Carothers et al. 2014). We included land cover change items because socioeconomic risks to sustainability were prominently featured (six out of seven items) among the risks produced by participants at the regional workshop. We aimed to also provide a platform for the groups to compare perceptions about land cover change.

(iii) Two propositions were stated to assess the two groups' perceptions of NS community resilience: (i) "Northern Alaska communities are prepared to face future economic and environmental challenges" and (b) "Northern Alaska communities are prepared to prosper even in turbulent times."

Likert question items probed whether the 15 items (from [i] and [ii]) pose risks to NS communities (true/false evaluation) and if true, about three dimensions of the risk: (1) impact, (2) local control over risk, and (3) changes in magnitude in the past 20 years (one of five levels of agreement allowed for each). These risk dimensions, impact, control, and magnitude, were identified as recurring concerns in the deliberations at the regional workshop.

\section{RESULTS}

The Tribal Council Group confirmed that all six elements of sustainability (Fig. 4) are still important to communities of the region. Results showed strong agreement with propositions relaying the importance of four of the elements ( $\mathrm{Mdn}=5$ or strongly agree), and agreement ( $\mathrm{Mdn}=4$ or agree) regarding the importance of cash economy, and education of the outside world about community goals and ways of living. These results confirmed that local control is a highly valued component of NS community sustainability.

\section{Agreement about the presence of risks, but differences in perceived uncertainties, local control over risks, and the future outlook for NS communities}

\section{Uncertainty}

Figure 5 depicts uncertainty as a function of the complexity and speed of changes as appraised by the two groups. Based on median scores, the Tribal Council Group ranked uncertainty in the socialecological system higher than the Manager Group. The councilors appraised the complexity of changes at a median score of 6 out of a possible 7 (IQR = 4-7), and the rate of changes at a median score of $5(\mathrm{IQR}=4-6)$. The Manager Group indicated complexity at a median score of $5(\mathrm{IQR}=3-6)$ and the rate of changes at 4 $(\mathrm{IQR}=3-6)$. In this schematic, the upper right corner stands for the region of highest uncertainty, where both the complexity of changes as well their speed are creating a difficult planning environment. The lower right corner represents uncertainty when problem complexity is low, but the speed of changes makes it challenging to apply proper solutions. The Manager Group ranked the perceived speed of social-ecological changes at the midpoint of the scale, and complexity higher, toward the region of uncertainty. The Tribal Council Group ranked both speed and complexity of changes on the higher end of the uncertainty scale.

Fig. 5. Uncertainty as a factor of the speed and complexity of changes in the North Slope social and environmental systems. Median values and interquartile ranges are depicted (shaded areas).

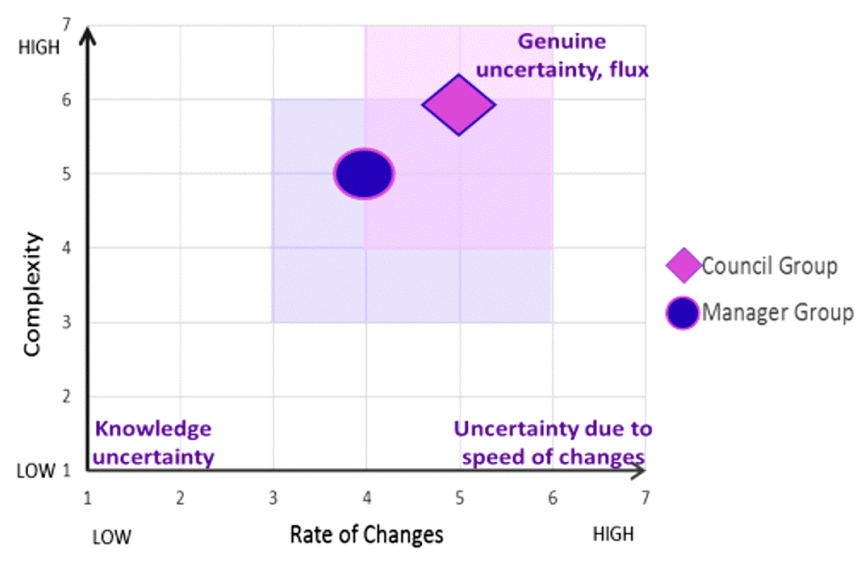

The factor analysis showed that "future outlook" is an important factor in how both groups perceive the rate of changes. The questions clustered under this factor asked respondents to evaluate the future of the region's social and ecological systems, and whether communities will continue to be sustainable. There was a statistically significant difference between the Tribal Council Group's optimistic views about sustainable futures and the Manager Group's neutral stance, based on factor scores (Appendix 2C). Interestingly, high rate of changes and high complexity scores did not prevent a positive outlook about future sustainability among councilors, while managers remained more pessimistic. Another noteworthy factor, "shifting socio-political capital," emerged as influential in the Tribal Council Group, and described a quickly changing regulatory environment. In the Manager Group, "shifting knowledge demands" emerged as an influential factor, describing constantly changing research, innovation, and monitoring needs as contributors to the perceived speed of changes. In both groups perceptions of complexity was influenced by factors that described an unpredictably, rapidly changing natural environment. But in the Tribal Council Group, the factor that seemed to impact perceptions of complexity the most was "global-local links." The statements clustered under this factor speak of a region whose social-ecological system is subject to outside drivers of change that strongly influence local processes.

Risks to sustainability: freelisted items

In response to the open-ended question about the top five risks to NS community sustainability, we analyzed 61 written responses containing 248 observations. The result of the analysis yielded 10 risk themes, shown in Table 1. Based on code frequency, the top 
three threats to sustainability according to the Tribal Council Group were risks from industrial development, ineffective decision making, and community health and health system issues. The Manager Group reported a struggling cash economy and environmental issues as the top two risks, while ineffective decision making and community health and health system issues were in third place. Notably, the greatest perceived risk for communities according to the Manager Group was a struggling cash economy, by a sizeable margin, at a code frequency nearly double that of second-place environmental issues. Environmental issues were identified as risks to sustainability, with near identical frequency by the Tribal Council Group, and linked to climate change impacts. Industrial development as a risk was most frequently mentioned by the Tribal Council Group in reference to ongoing heavy air pollution from onshore activities, and potential risks posed by offshore accidents. Ineffective decision making ranked high in both groups, with the Tribal Council Group pointing to bad regulations, and the Manager Group naming divided local interests, as the main cause.

Table 1. Coded risks: frequency results. Top subcategories: (a) misguided regulations; (b) divided local interests; (c) climate change; (d) air pollution, offshore accidents; (e) single-resource economy; (f) substance abuse.

\begin{tabular}{lcc}
\hline \hline Top-level theme & \multicolumn{2}{c}{ Frequency } \\
\cline { 2 - 3 } & $\begin{array}{c}\text { Tribal Council } \\
\text { Group }\end{array}$ & Manager Group \\
\hline Struggling cash economy & 8 & $32^{\mathrm{e}}$ \\
High cost of living & 6 & 6 \\
Risks to culture & 17 & 8 \\
Ineffective decision making & $23^{\mathrm{a}}$ & $16^{\mathrm{b}}$ \\
Risks from industrial development & $25^{\mathrm{d}}$ & 6 \\
Education issues & 6 & 7 \\
Environmental issues (not directly & $19^{\mathrm{c}}$ & $18^{\mathrm{c}}$ \\
related to industrial development) & & $16^{\mathrm{f}}$ \\
Community health and health & $22^{\mathrm{f}}$ & 2 \\
system issues & & 9 \\
Risks to subsistence & 1 & \\
Demographic changes & 1 &
\end{tabular}

Impacts from, control over, and magnitude of changes

Four of eight land cover change items listed in the survey were marked as risks either unanimously or by the majority of each tribal council: less snow in winter, permafrost thaw, later fall freeze-up, and earlier spring breakup. All six socioeconomic risk items were deemed risks in the Tribal Group in the same manner: problems with health and health services, issues around education in the school system and transmission of traditional knowledge, ineffective decision making, industrial development, and risks to culture. The Manager Group identified all land cover changes, and all socioeconomic items as risks to NS community sustainability. There was no significance of association between the results and the respondents' affiliation with a particular level of government (state or federal).

Median and IQR values for risk impact and magnitude suggest that both groups perceive land cover changes and socioeconomic risks to be highly impactful on sustainability, and having increased in intensity in the past 20 years. Figures $6 a, 6 b$, and $6 \mathrm{c}$ illustrate these results. The Tribal Council Group ranked the impacts from socioeconomic risk and the magnitude of land cover changes at the highest priority ( $\mathrm{Mdn}=5$ or very high and increased greatly, respectively). The Manager Group ranked these same dimensions as high $(\mathrm{Mdn}=4)$ and increased $(\mathrm{Mdn}=4)$. In response to the statement "NS communities are capable of managing or controlling this risk," feedback from the Tribal Council Group showed a mainly neutral view (dispersed between agreement and neutral) for land cover changes, but for socioeconomic risks, feedback showed agreement $(\mathrm{Mdn}=4)$. With respect to perceptions of communities' capacity to manage or control risks, the Manager Group showed a neutral point of view, with opinions spread between agreement and disagreement.

\section{Are North Slope communities resilient?}

The majority of respondents in the Tribal Council Group agreed with the propositions probing perceptions of community resilience $(\mathrm{Mdn}=4$, agree) with agreement spread between neutral to strong agreement (IQR = 3-5). The Manager Group's score on the other hand $(\mathrm{Mdn}=2$, disagree, $\mathrm{IQR}=2-3)$ indicated that most in that group did not consider NS communities resilient to future challenges.

\section{DISCUSSIONS}

Council members' perception of uncertainty was most influenced by the unpredictability of changes that are occurring, and by the complexity of global connections with the region's changing social-ecological system. This perceived uncertainty appeared compounded by a difficult regulatory environment and shifting social and political capital, but mitigated by a positive outlook on the region's future sustainability. In the Manager Group, rapid environmental changes and constantly shifting science and monitoring needs were found to be the most prominent factors in an otherwise moderate sense of uncertainty. This finding corresponds with a somewhat negative outlook on future community sustainability in the region. The council group, unlike the manager cohort, had a more positive view of the future, despite perceiving greater uncertainties due to social-ecological changes. These differences suggest a perception of resilience in tribal councilors independent of complexity and speed of changes, suggesting that tribal councils have self confidence in their capacity to navigate changes and persist into the future.

Our results regarding the presence of certain risks and uncertainties in the NS region indicate that tribal leaders and resource management professionals were mostly in agreement. When evaluating the same set of risks, the majority of both groups believed that risks related to the impacts of change on community sustainability are high and have increased in magnitude in the years prior. In the Tribal Council Group however, risk impacts and magnitude perceptions were spread between high to very high and increased to increased greatly, respectively. In comparison, perceptions of the Manager Group were between moderate to high, and stayed the same to high, respectively. Likewise, the Tribal Council Group perceived higher levels of uncertainties for the NS region due to rapid, complex social and ecological changes, though both groups confirmed uncertainties. The fact that risk impacts, magnitude, and overall uncertainty are similarly evaluated by both groups suggests basic shared understanding of some local-level conditions and quality of cross-scale communication between local and nonlocal actors. But the level or extent of risks perceived by the local and nonlocal experts was different. 
Fig. 6. North Slope risks to community sustainability. Risk dimensions color coded from red (greatest risk) to green (least risk), coloring of icons indicate Mdn values, gradient corresponds to IQR. (a) Risk impacts to community sustainability from land cover changes and socioeconomic issues (color gradient based on Mdn and IQR from $1=$ very low to $5=$ very high), (b) level of agreement with statement that communities are managing/controlling risks (color gradient based on Median and IQR from $1=$ strongly agree to $5=$ strongly disagree), and (c) magnitude of risks (color gradient based on Median and IQR from $1=$ decreased greatly to $5=$ increased greatly).
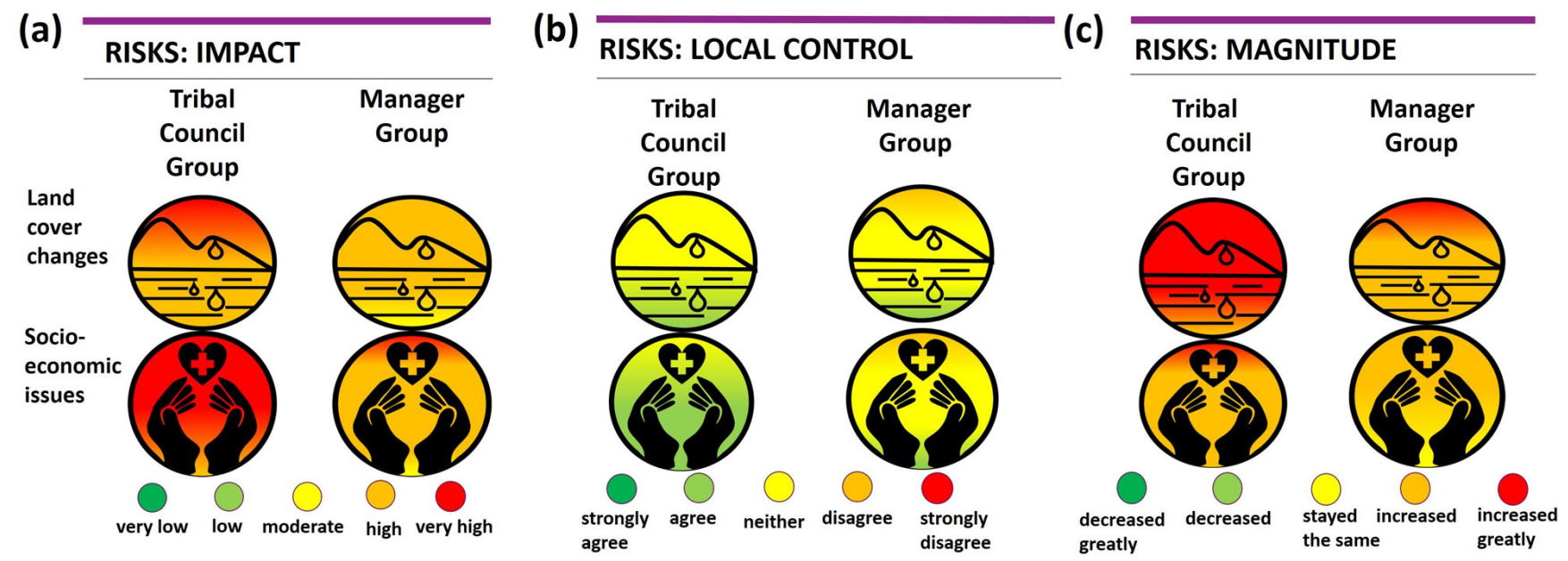

An important distinction in the two groups was made in the evaluations of land cover changes as risks. The Manager Group identified all land cover propositions as risks to community sustainability. The Tribal Council Group on the other hand collectively determined only four land cover changes as threats to the region's sustainability. This suggests a gap in perspectives between local and nonlocal experts about risks to be confronted because of changes in the NS biophysical environment.

The prioritization of risks requiring the attention of decision makers (Table 1) was assessed quite differently by the two groups. Such differences in the need for action can lead to disagreement and conflict, and can limit adaptive responses in the face of changes. In the open-ended risk question, the Manager Group highlighted what it viewed as a struggling cash economy. These respondents noted the need for economic growth, wage jobs, and improved infrastructure as the most urgent threats to the sustainability of NS communities. This result implies an awareness by the Manager Group that economic development is important and financial capital is needed to bolster healthy, sustainable NS communities. The Tribal Council Group, however, pointed to the negative impacts of industrial development as posing the greatest risk to sustainability, with ineffective inclusion of locals in higher level decisions a close second. Planning the trajectory of development, i.e., when and where to invest or treat risks for optimal sustainability, especially at times of rapid adaptation to climate change, has to take place in the local context (Lynch and Brunner 2007). As one councilor remarked about economies of priority, "There are two main economies, subsistence and cash, and subsistence comes first" (Respondent A 2016). Yet another councilor confirmed the importance of observing community ties with the land in development decisions: "We are losing our hunting grounds ... where will the hunters go when the land is used up?" (Respondent B 2016).
These findings confirm the importance of local control as a vital element to NS community sustainability, and as a source of vulnerability when not present. Tribal councilors did not indicate that they had lost control over risks that threaten communities. But they did indicate that they do not feel in control of decisionmaking processes, commonly referencing the problems of ineffective decision making and misguided regulations. During interviews, similar comments were made by councilors: "There is no meaningful inclusion [of locals at higher levels], we are a compromised people" (Respondent C 2016). "Slow the progress down and gain more info from Iñupiat people because we are fully impacted" (Respondent D 2016). Our results do not suggest that tribal leaders feel that industrial development must cease in order to eliminate risks. NS community sustainability is indeed interlinked with the availability of opportunities to develop economically and in harmony with subsistence lifeways. But local (in this case Iñupiat) approaches to problem definition and community response were viewed as vital for sustainable outcomes.

Local autonomy over decisions is realized through sovereignty in practice (Cornell and Kalt 1998), defined here as tribal institutions and their elected tribal representatives defining problems, formulating strategies for addressing problems, and overseeing the implementation of solutions pertaining to homelands and resources used by the communities. When local institutions have significant authority in setting research priorities and policies for managing resources, they can ensure a better fit with the biophysical and social domains in which they operate (Young 2013).

In spite of otherwise similar perceptions of uncertainty and ever increasing risks by the two groups, the Tribal Council Group was positive about their communities' resilience. This may be due to the rich history of successful adaptation and demonstrated 
resilience that has allowed NS communities to thrive in the past under adverse conditions. In spite of reporting increasing risks due to land cover changes and increased socioeconomic risks, tribal council members did not perceive a loss of control or lack of capacity to manage risks. These findings corroborate the prominent role of future outlook in shaping both groups' perception of speed of changes. The high confidence of communities' ability to manage risks suggests that community leaders feel they have thus far managed the necessary resources for adaptation.

In many NS communities traditional practices, such as the sharing of wild foods, were noted as an important cultural asset in coping with possible challenges in the future. In times of rapid environmental changes compounded by socioeconomic hardships, the sharing of wild foods is seen by Inupiat as both tradition and as a way of sustaining community through hard times (Kofinas et al. 2016). For example, when the cash economy is struggling and it is especially difficult to supplement diets with high-priced store-bought foods, subsistence households that share their take provide a source of resilience in the community. A Tribal Councilor explained the value of sharing for community sustainability, especially around whaling customs, in this case muktuk or whale blubber: "We are very high in sharing ... whaling captains share muktuk, and fermented muktuk with the community" (Respondent E 2016). Networks of sharing around traditional foods has been a source of community resilience in rural Alaska. As noted by BurnSilver et al. (2016), these traditions have persisted and are revered by Iñupiat, even with communities' engagement in the cash economy, and continue to be viewed as sources for resilience for facing future changes.

Because the legacies of outside interference have had detrimental results on Alaska Indigenous communities in the past (EvansCampbell 2008), participants may have been understandably reluctant to report diminishing control over risks. What is certain however, is that the Tribal Council Group consistently reported confidence in communities' adaptability, resilience, and hope for the future, and the belief that local knowledge should drive resource management decisions. Clearly, village leaders believe that Indigenous knowledge should have an important role as pillars in advising policy about risks and appropriate response strategies.

The Manager Group's lack of confidence in the resilience of NS communities may very well stem from an acknowledgment of the magnitude and complexities of the challenges confronting villages, as opposed to skepticism about local resourcefulness. For example, in the open-ended question about risks, some respondents in the Manager Group also acknowledged the risk of outside interference and demand for the region's resources. One respondent commented that there is a "significant lack of understanding toward the communities by the Alaska Legislature and much of Alaska's general population" (Respondent F 2016), while others pointed to "outside societal pressures" (Respondent G 2015) and "outside interest in Alaska's industry" as risks to community sustainability (Respondent H 2015). The lack of confidence may also be affected indirectly by deeply rooted legacies of paternalism (Black 2009). In future studies an examination of potential interactions between nonresident experts' main area of expertise and their risk perceptions would complement and further refine the findings of this study. The overlap of multiple expertise areas prevented such analysis in our research.

Institutional proximity to communities and stakeholders is not a panacea for maladaptation. There are cases where institutions at local social-ecological scales are not equipped to handle optimal adaptive responses. Where local governments do not foster community participation within governance structures, issues of mistrust can result from a pattern of maladaptive outcomes. For example a case study of urban flood risk management in Ekurhuleni, South Africa showed that a history of reactionary, stop gap management of risks and a disconnect from the longterm needs of the community, damaged public opinion of the municipal government as a legitimate institution to manage disaster preparedness (Fatti and Patel 2013). Similarly, a study of adaptation strategies concerning Australia's Great Barrier Reef showed that adaptation measures developed using a short-term view and a top-down approach are major threats to effective climate adaptation, while adequate legal and policy environment, financial, and technical support, and credible and relevant information enable local adaptation (Fidelman et al. 2013). Cases such as these highlight the importance of local adaptation as a priority for multilevel governance of climate change adaptation, and the role of institutional fit in successful outcomes.

\section{CONCLUSIONS}

We explored differences in how risks are perceived and prioritized by NS tribal councilors and nonresident resource management professionals. Results revealed that the pillars of sustainable communities are under pressure from rapid, complex changes in the social-ecological system. The traditions, knowledge, and practices that have served NS villages well through past cycles of adaptation depended to a great extent on local control over decisions and subsistence lifeways. In comparison, local control has diminished and conflicting views among decision makers across scales has gained prominence in influencing adaptive action. Such conflicts constrain implementation strategies for coping with change. Better awareness of differences in perception can provide insight and the basis for dialogue in planning.

Results showed that ranking of risks in terms of most critical impacts for community sustainability produce two dissimilar lists. These lists would produce very different road maps for meaningful intervention or adaptive action in response to risks. In interviews with tribal leaders social and political issues as risks featured heavily in discussions compared with ecological problems. This does not suggest that the rapid biophysical transformations under way in the Arctic do not impact NS communities. Instead what we found was that the main barriers that are perceived at the local level as threats to effective adaptation are rooted in the social and political processes that are in many cases not responsive to locallevel priorities. These observations are important resource management concerns. Especially in regions where people rely on healthy local ecosystem services for their livelihood, the long-term impacts from resource development (both renewable and nonrenewable) have to be balanced with local-scale priorities. Because those local-scale priorities often indeed include economic growth and industrial development, power-sharing institutional arrangements are needed that shape the pace and scale of development in ways that facilitate adaptation and build resilience. 
Tribal councils have the expertise and knowledge to institutionalize Iñupiat approaches to problem avoidance, problem definition, and community response (Conn 1985). The inclusion of local values and goals, which are reflected in villagers' perceptions of risk, are critical in avoiding unanticipated and unwanted outcomes. In the NS region, the choice of what actors at what scale determine how risks are evaluated and what responses are deployed can significantly determine the effectiveness of environmental stewardship and adaptive outcomes.

Responses to this article can be read online at: http://www.ecologyandsociety.org/issues/responses. php/11776

\section{Acknowledgments:}

The authors are grateful to the workshop participants in the Northern Alaska Scenarios Project, the village tribal councils of the North Slope Borough, and all the employees of the various State of Alaska and U.S. federal departments and agencies, who contributed to this research. The helpful research assistance of Gabriela Halas interviewing village tribal council members is also gratefully acknowledged. We are thankful for the helpful comments from the reviewers who helped to improve on an earlier version of this manuscript. This study was supported by the National Science Foundation Alaska Experimental Program to Stimulate Competitive Research (Alaska EPSCoR) NSF award \#OIA-1208927 and the State of Alaska, and the ArcSEES Project NSF award \#1263850.

\section{Data Availability:}

All relevant data underlying the findings of this manuscript have been made available. Prior to recruitment and data collection, the research procedures were approved for use with human subjects (University of Alaska Fairbanks IRB\# 764745-5) and informed consent was obtained from all participants. Respondents $A, B, C$, $D$ and $E$ were administered surveys between January - March 2016 on location in Nuiqsut, Barrow, Point Hope and Utqiagivik (listed in no particular order). Data and transcripts are on file with first author. Respondents $F, G$ and $H$ were administered surveys between July 2015 - May 2016. Respondent F completed an electronic version (https://www. surveymonkey.coml). Respondents $G$ and $H$ were administered surveys on location in Fairbanks. Data and transcripts are on file with first author.

\section{LITERATURE CITED}

Adger, W. N., S. Dessai, M. Goulden, M. Hulme, I. Lorenzoni, D. R. Nelson, L. O. Naess, J. Wolf, and A. Wreford. 2009. Are there social limits to adaptation to climate change? Climatic Change 93:335-354. https://doi.org/10.1007/s10584-008-9520-z

Ahtuangaruak, R. 2015. Broken promises: the future of Arctic development and elevating the voices of those most affected by it-Alaska Natives. Politics, Groups, and Identities 3:673-677. https://doi.org/10.1080/21565503.2015.1080618
Alaska Native Science Commission (ANSC). 2009. The voice of the real people: North Slope communities on NPR - a social science plan. Report Prepared for the Bureau of Land Management. Alaska Native Science Commission, Anchorage, Alaska, USA.

Aven, T. 2016. Risk assessment and risk management: review of recent advances on their foundation. European Journal of Operational Research 253:1-13. https://doi.org/10.1016/j.ejor.2015.12.023

Baglin, J. 2014. Improving your exploratory factor analysis for ordinal data: a demonstration using FACTOR. Practical Assessment, Research \& Evaluation 19:5.

Berkes, F. 1999. Sacred ecology: traditional ecological knowledge and management systems. Taylor \& Francis, Philadelphia, Pennsylvania, USA.

Black, J. E. 2009. Native resistive rhetoric and the decolonization of American Indian removal discourse. Quarterly Journal of Speech 95:66-88. https://doi.org/10.1080/00335630802621052

Blair, B., A. L. Lovecraft, and G. P. Kofinas. 2014. Meeting institutional criteria for social resilience: a nested risk system model. Ecology and Society 19(4):36. https://doi.org/10.5751/ ES-06944-190436

BurnSilver, S., J. Magdanz, R. Stotts, M. Berman, and G. Kofinas. 2016. Are mixed economies persistent or transitional? Evidence using social networks from Arctic Alaska. American Anthropologist 118:121-129. https://doi.org/10.1111/aman.12447

Carothers, C., C. Brown, K. J. Moerlein, J. A. López, D. B. Andersen, and B. Retherford. 2014. Measuring perceptions of climate change in northern Alaska: pairing ethnography with cultural consensus analysis. Ecology and Society 19(4):27. https:// doi.org/10.5751/ES-06913-190427

Chapin III, F. S., G. P. Kofinas, and C. Folke. 2009. Principles of ecosystem stewardship: resilience-based natural resource management in a changing world. Springer Science + Business Media, New York, New York, USA. https://doi.

org/10.1007/978-0-387-73033-2

Cochran, P., O. H. Huntington, C. Pungowiyi, S. Tom, F. S. Chapin III, H. P. Huntington, N. G. Maynard, and S. F. Trainor. 2013. Indigenous frameworks for observing and responding to climate change in Alaska. Pages 49-59 in J. Koppel Maldonado, B. Colombi, and R. Pandya, editors. Climate change and Indigenous peoples in the United States: impacts, experiences and actions. Springer, Cham, Switzerland. https://doi. org/10.1007/978-3-319-05266-3 5

Conn, S. 1985. Inuit village councils in Alaska-an historical model for effectuation of aboriginal rights? Études/Inuit/Studies 9:43-59.

Cornell, S., and J. P. Kalt 1998. Sovereignty and nation-building: the development challenge in Indian country today. American Indian Culture and Research Journal 22:187-214. https://doi. org/10.17953/aicr.22.3.1v45536553vn7j78

de Winter, J. C. F., D. Dodou, and P. A. Wieringa. 2009. Exploratory factor analysis with small sample sizes. Multivariate Behavioral Research 44:147-181. https://doi.org/10.1080/00273170902794206 
Douglas, M., and A. Wildavsky. 1982. Risk and culture: an essay on the selection of technical and environmental dangers. University of California Press, Berkeley, California, USA.

Evans-Campbell, T. 2008. Historical trauma in American Indian/ Native Alaska communities: a multilevel framework for exploring impacts on individuals, families, and communities. Journal of Interpersonal Violence 23:316-338. https://doi.org/10.1177/0886$\underline{260507312290}$

Fath, B. D., C. A. Dean, and H. Katzmair. 2015. Navigating the adaptive cycle: an approach to managing the resilience of social systems. Ecology and Society 20(2):24. https://doi.org/10.5751/ ES-07467-200224

Fatti, C. E., and Z. Patel. 2013. Perceptions and responses to urban flood risk: implications for climate governance in the South. Applied Geography 36:13-22. https://doi.org/10.1016/j. apgeog.2012.06.011

Fidelman, P. I., A. M. Leitch, and D. R. Nelson. 2013. Unpacking multilevel adaptation to climate change in the Great Barrier Reef, Australia. Global Environmental Change 23:800-812. https://doi. org/10.1016/j.gloenvcha.2013.02.016

Fischhoff, B., P. Slovic, S. Lichtenstein, S. Read, and B. Combs. 1978. How safe is safe enough? A psychometric study of attitudes towards technological risks and benefits. Policy Sciences 9:127-152. https://doi.org/10.1007/BF00143739

Folke, C., L. Pritchard, F. Berkes, J. Colding, and U. Svedin. 2007. The problem of fit between ecosystems and institutions: ten years later. Ecology and Society 12(1):30. https://doi.org/10.5751/ ES-02064-120130

Ford, J. D., L. Cameron, J. Rubis, M. Maillet, D. Nakashima, A. C. Willox, and T. Pearce. 2016. Including indigenous knowledge and experience in IPCC assessment reports. Nature Climate Change 6:349-353. https://doi.org/10.1038/nclimate2954

Freeman, M. M. 1989. Graphs and gaffs: a cautionary tale in the common-property resources debate. Pages 92-109 in F. Berkes, editor. Common property resources: ecology and community-based sustainable development. Belhaven, London, UK.

Glaser, M., G. Krause, R. S. Oliveira, and M. Fontalvo-Herazo. 2010. Mangroves and people: a social-ecological system. Pages 307-351 in U. Saint-Paul and H. Schneider, editors. Mangrove dynamics and management in North Brazil. Springer-Verlag, Berlin, Germany. https://doi.org/10.1007/978-3-642-13457-9 21

Hovelsrud, G. K., J. L. White, M. Andrachuk, and B. Smit. 2010. Community adaptation and vulnerability integrated. Pages 335-348 in G. K. Hovelsrud and B. Smit, editors. Community adaptation and vulnerability in Arctic regions. Springer, Dordrecht, The Netherlands. https://doi.org/10.1007/978-90-481-9174-1 14

Huntington, H. P. 2000. Using traditional ecological knowledge in science: methods and applications. Ecological Applications 10:1270-1274. https://doi.org/10.1890/1051-0761(2000)010[1270: UTEKIS]2.0.CO;2

Kahan, D. M., E. Peters, M. Wittlin, P. Slovic, L. L. Ouellette, D. Braman, and G. Mandel. 2012. The polarizing impact of science literacy and numeracy on perceived climate change risks. Nature Climate Change 2:732-735. https://doi.org/10.1038/nclimate1547
Kimmel, M. 2014. Sovereigns, not stakeholders: an Alaskan study in fate control. The Yearbook of Polar Law Online 6:318-339. https://doi.org/10.1163/1876-8814011

Kofinas, G., S. B. BurnSilver, J. Magdanz, S. Rhian, and M. Okada. 2016. Subsistence sharing networks and cooperation: Kaktovik, Wainwright, and Venetie, Alaska. BOEM Report 2015-023. School of Natural Resources and Extension, University of Alaska Fairbanks, USA. [online] URL: https:// www.boem.gov/sites/default/files/boem-newsroom/Library/ Publications/2015/BOEM-2015-23.pdf

Kruse, J. A., R. G. White, H. E. Epstein, B. Archie, M. Berman, S. R. Braund, F. S. Chapin III, J. Charlie Sr, C. J. Daniel, J. Eamer, N. Flanders, B. Griffith, S. Haley, L. Huskey, B. Joseph, D. R. Klein, G. P. Kofinas, S. M. Martin, S. M. Murphy, W. Nebesky, C. Nicolson, D. E. Russell, J. Tetlichi, A. Tussing, M. D. Walker, and O. Y. Young. 2004. Modeling sustainability of arctic communities: an interdisciplinary collaboration of researchers and local knowledge holders. Ecosystems 7:815-828. https://doi. org/10.1007/s10021-004-0008-Z

Larsen, J. N., G. Fondahl, and P. Schweitzer. 2010. Arctic social indicators: a follow-up to the Arctic Human Development Report. Nordic Council of Ministers, Copenhagen, Denmark. [online] URL: http://library.arcticportal.org/712/1/Arctic Social Indicators NCoM.pdf

Lazrus, H. 2015. Risk perception and climate adaptation in Tuvalu: a combined cultural theory and traditional knowledge approach. Human Organization 74:52-61. https://doi.org/10.17730/ humo.74.1.q0667716284749m8

Lichtenstein, S., and P. Slovic. 2006. The construction of preference. Cambridge University Press, Cambridge, UK. https:// doi.org/10.1017/CBO9780511618031

Lindgren, M., and H. Bandhold. 2009. Scenario planning: the link between future and strategy. Revised and updated. Palgrave MacMillan, Basingstoke, UK. https://doi.org/10.1057/9780230233584

Lynch, A. H., and R. D. Brunner. 2007. Context and climate change: an integrated assessment for Barrow, Alaska. Climatic Change 82:93-111. https://doi.org/10.1007/s10584-006-9165-8

McMillen, H., T. Ticktin, and H. K. Springer. 2017. The future is behind us: traditional ecological knowledge and resilience over time on Hawai'i Island. Regional Environmental Change 17:579-592. https://doi.org/10.1007/s10113-016-1032-1

Meek, C. L., A. L. Lovecraft, R. Varjopuro, M. Dowsley, and A. T. Dale. 2011. Adaptive governance and the human dimensions of marine mammal management: implications for policy in a changing North. Marine Policy 35:466-476. https://doi. org/10.1016/j.marpol.2010.10.021

Meredith, M., M. Sommerkorn, S. Cassotta, C. Derksen, A. Ekaykin, A. Hollowed, G. Kofinas, A. Mackintosh, J. MelbourneThomas, M. M. C. Muelbert, G. Ottersen, H. Pritchard, and E. A. G. Schuur. 2019. Polar regions. In H. O. Pörtner, D. C. Roberts, V. Masson-Delmotte, P. Zhai, M. Tignor, E. Poloczanska, K. Mintenbeck, A. Alegría, M. Nicolai, A. Okem, J. Petzold, B. Rama, and N. M. Weyer, editors. IPCC special report on the ocean and cryosphere in a changing climate. In press. 
Raynolds, M. K., D. A. Walker, K. J. Ambrosius, J. Brown, K. R. Everett, M. Kanevskiy, G. P. Kofinas, V. E. Romanovsky, Y. Shur, and P. J. Webber. 2014. Cumulative geoecological effects of 62 years of infrastructure and climate change in ice-rich permafrost landscapes, Prudhoe Bay Oilfield, Alaska. Global Change Biology 20:1211-1224. https://doi.org/10.1111/gcb.12500

Young, O. R. 2002. The institutional dimensions of environmental change: fit, interplay, and scale. MIT Press, Cambridge, Massachusetts, USA. https://doi.org/10.7551/mitpress/3807.001.0001

Young, O. R. 2013. Sugaring off: enduring insights from longterm research on environmental governance. International Environmental Agreements: Politics, Law and Economics 13:87-105. https://doi.org/10.1007/s10784-012-9204-z 
Appendix 1: Cross-impact questionnaire

SOCIAL-ECOLOGICAL COMPLEXITY QUESTIONS: Completely disagree (1)--- Completely agree (7)

a) SOCIAL COMPLEXITY INDEX:

SX_1 Actions taken by and in our borough affect the State of Alaska and region strongly.

SX_2 The business environment is very complex with many unclear factors and relationships affecting our borough.

SX_3 Actions taken at the Pan-Arctic level affect lives strongly in our borough.

SX_4 New and unpredictable economic and political events and interests in the Arctic are constantly occurring

SX_5 It is very difficult to foresee and anticipate future changes in Northern Alaska.

SX_6 The sustainability of Northern Alaska communities is highly influenced by unpredictable public policies

SX_7 There are many unexpected threats that our borough has to cope with.

\section{b) ENVIRONMENTAL COMPLEXITY INDEX:}

EX_1 Environmental changes in the northern region of Alaska will affect the state and region strongly

EX_2 The Arctic environment is very complex with many unclear factors and relationships influencing our borough.

EX_3 It is very difficult to foresee environmental change

EX_4 New and unpredictable environmental changes are constantly occurring

EX_5 The two borough's environment is highly influenced by unpredictable public policies.

EX_6 The sustainability of Northern Alaska communities is highly influenced by unpredictable environmental challenges.

\section{c) SOCIAL SPEED OF CHANGES INDEX:}

SC_1 Regional and global markets will grow for several years in ways that support sustainability in our borough.

SC_2 Opportunities for our borough look good for the next few years.

SC_3 Our borough is constantly having to cope with risks that are changing.

SC_4 The regulatory environment is continually changing.

SC_5 Social values in society are continually changing.

SC_6 There is high demand placed on Northern Alaska communities having to innovate because of new rules and regulations. 


\section{d) ENVIRONMENTAL SPEED OF CHANGES INDEX:}

EC_1 The future of Northern Alaska's environment looks positive in the coming years.

EC_2 Northern Alaska's environment will support the sustainability goals of its communities in the coming years.

EC_3 There is high demand placed on northern Alaska's environment to provide resources to meet demands from users.

EC_4 Social values outside our Northern Alaska region toward the environment are continually changing

EC_5 Environmental research and monitoring needs in Northern Alaska are constantly changing.

EC_6 The rate of innovation in environmental research and stewardship is high. 
APPENDIX 2A: Exploratory factor analysis background.

The sampling adequacy and factorability of variables were tested using several methods. First, the factorability of change and complexity variables were examined in both the council and manager groups using correlation coefficients (reasonable at $>.3$ ). Though our sample sizes were small, satisfactory factor recovery has been shown possible under conditions similar to ours. De Winter found that with a sample size $N=17-21$, recovery can be successful at factor loadings $\lambda=0.8$, number of factors $f=3-4$, and number of variables $p=6$ 12 (de Winter et al., 2009). Standard measurements of sampling adequacy returned above recommended values (Kaiser-Meyer-Olkin measure $>.5$ as per Kaiser (1974); anti-image correlation matrix diagonals $>.5$; and $\mathrm{p}<.05$ Bartlett's test of sphericity in all cases).

We retained factors based on the Kaiser Criterion, Scree test and cumulative percent of variance, in order to retain meaningful factors with satisfactory eigenvalues. Using $\lambda$ factor loadings cross-loadings of items were examined to find items with significant correlation with multiple factors. Variables with $\lambda$ below 0.3 were eliminated one at a time and the factor extraction repeated. Final models were chosen based on (i) the leveling off of eigenvalues on the scree plot, (ii) difficulty of interpreting subsequent factors (insufficient $\lambda$ values, heavy cross-loadings), and (iii) final factor correlation matrix with all correlations less than 0.6. The factors were given descriptive labels based on interpretations of common themes and relationships between the variables. In naming the clusters, attention was paid to the $\lambda$ values. Any factor loading above 0.6 is considered a strong association, and above 0.4 is considered moderate (Comrey and Lee, 1992; Matsunaga, 2015). Based on these, the relative prominence of variables in addition to their theme played a role in the chosen labels. Where possible and applicable, identical names were given to factors in the council and manager groups if the combination of variables expressed identical themes, even if the exact combination of items was different.

\section{Literature Cited}

Baglin J. 2014. Improving your exploratory factor analysis for ordinal data: A demonstration using FACTOR. Practical Assessment, Research \& Evaluation 19: 2.

Comrey, A. \& Lee, H. 1992. A first course in factor analysis (2nd edn.) lawrence earlbaum associates. Publishers: Hillsdale, New Jersey.

De Winter J, Dodou D and Wieringa P. 2009. Exploratory factor analysis with small sample sizes. Multivariate Behavioral Research 44: 147-181.

Kaiser, H.F. 1974. An index of factorial simplicity. Psychometrika, 39, 31-36.

Matsunaga, M. 2015. How to factor-analyze your data right: Do's, don'ts, and how-to's. International Journal of Psychological Research, 3, 97-110.

Preacher, K.J. and MacCallum, R.C., 2002. Exploratory factor analysis in behavior genetics research: Factor recovery with small sample sizes. Behavior genetics, 32(2), pp.153-161. 


\section{APPENDIX 2B: Exploratory factor analysis results}

Table A2.B.1 Social-ecological system changes and complexity models shown. Variable names: SC = social system change, $\mathrm{EC}=$ environmental system change, $\mathrm{SX}=$ social system complexity, $\mathrm{EX}=$ environmental system complexity. ${ }^{*}$ Reverse coded variables: In the calculation of rate of changes, these statements were reverse coded because they were worded positively, unlike the rest of the items. Positive outlook about the future (higher scores) indicate less uncertainty in the environment, and ability to forecast future trends. These items were reverse scored to keep them on the same scale with other variables. The ability to project future outcomes presupposes continuity of trends and the ability to steer the system toward desired states - traits of low uncertainty in a system (Stacey 2007, Tschakert, et al. 2014).

\section{SES changes factors:}

Council Group
Unpredictable risks
EC_6 The sustainability of Northern Alaska
communities is highly influenced by unpredictable
environmental challenges.
SC_3 The two boroughs are constantly having to cope
with risks that are changing
EC_5 Environmental research and monitoring needs in
Northern Alaska are constantly changing
Shifting social and political capital
SC_4 The regulatory environment is continually changing
SC_5 Social values in society are continually changing
Future outlook
revEC_1* The future of Northern Alaska's environment
looks positive in the coming years.
revEC_2* Northern Alaska's environment will support
the sustainability goals of its communities in the coming
years.
Kaiser-Meyer-Olkin measure:
Bartlett's Test - Sig.
Eliminated variables: EC_3, EC_4, SC_1, SC_2, SC_6

SES complexity factors:

\section{Council Group}

Global-local links

EX_2 The Arctic environment is very complex with many unclear factors and relationships influencing the two boroughs.

SX 3 Actions taken at the Pan-Arctic level affect

lives strongly in the two boroughs.

EX_4 New and unpredictable environmental changes are constantly occurring.

\section{Unpredictable policies}

SX_6 The sustainability of Northern Alaska communities is highly influenced by unpredictable public policies

EX_5 The two borough's environment is highly influenced by unpredictable public policies.

\section{Changing economy $\&$ environment}

SX_2 The business environment is very complex with 0.86 many unclear factors and relationships affecting the two boroughs

EX_1 Environmental changes in the northern region of Alaska will affect the state and region strongly

Kaiser-Meyer-Olkin measure:

Bartlett's Test - Sig.

Eliminated: $E X \_6, S X \_1, S X \_3, S X \_4, S X \_5, S X \_7$

$\lambda$

\section{Manager Group}

Future outlook

0.77 revEC_1* The future of Northern Alaska's environment looks positive in the coming years. revEC_2* Northern Alaska's environment will

0.75 support the sustainability goals of its communities in the coming years.

0.56 revSC_2* Opportunities for the two boroughs look good for the next few years

revSC_1* Regional and global markets will grow for several years in ways that support sustainability in the two boroughs.

\section{Shifting knowledge demands}

SC_6 There is high demand placed on Northern

0.81 Alaska communities having to innovate because of new rules and regulations

0.50 SC_4 The regulatory environment is continually changing

EC_5 Environmental research and monitoring needs in Northern Alaska are constantly changing

Kaiser-Meyer-Olkin measure:

Bartlett's Test - Sig.

Eliminated variables: $E C \_3, E C \_4, E C \_6, S C-3, S C \_5$

\section{Manager Group}

0.90 EX_6 The sustainability of Northern Alaska

0.60 EX_4 New and unpredictable environmental changes

0.43 EX_1 Environmental changes in the northern region 0.79 two boroughs.

$0.71 \quad$ Unpredictable policies

0.42 SX_4 New and unpredictable economic and political Unpredictable environmental changes communities is highly influenced by unpredictable environmental challenges are constantly occurring of Alaska will affect the state and region strongly EX_2 The Arctic environment is very complex with many unclear factors and relationships influencing the

SX_7 There are many unexpected threats that the two boroughs have to cope with.

SX_6 The sustainability of Northern Alaska communities is highly influenced by unpredictable public policies

EX_5 The two borough's environment is highly influenced by unpredictable public policies. events and interests in the Arctic are constantly occurring

$\lambda$

Eliminated: $E X \_3, S X \_1, S X \_2, S X \_3, S X \_5$
Kaiser-Meyer-Olkin measure: 


\section{Literature Cited}

Stacey RD. 2007. Strategic management and organisational dynamics: The challenge of complexity to ways of thinking about organisations. Pearson education.

Tschakert P, Dietrich K, Tamminga K, et al. 2014. Learning and envisioning under climatic uncertainty: An African experience. Environment and Planning A. 46:1049-1068. 


\section{APPENDIX 2C: Factor scores}

As a final step, composite scores were created for each of the factors, based on the mean of the items in each, ignoring $\lambda$ values (Table A1.C.1). DiStefano et al. (2009) noted that this unrefined method has been established as appropriate for exploratory research (Hair et al., 2009; Tabachnick et al., 2001). Because this study aims to simplify complex and dynamic human perceptions, but without claiming to predict them, Exploratory Factor Analysis and unrefined factor scores produce adequate basis for such discussions.

Table A2.C.1 Factor scores (mean scores indicated)

\begin{tabular}{|c|c|c|}
\hline Council Group & Factor score & SD \\
\hline \multicolumn{3}{|l|}{ SES Changes } \\
\hline 1. Unpredictable risks & 5.3 & 1.3 \\
\hline 2. Shifting social and political capital & 5.3 & 1.2 \\
\hline 3. Future outlook* & $4.6(\mathrm{Mdn}=5)$ & 1.4 \\
\hline \multicolumn{3}{|l|}{ SES Complexity } \\
\hline 1. Global-local links & 5.7 & 1.2 \\
\hline 2. Unpredictable policies & 5.1 & 1.5 \\
\hline 3. Changing economy and environment & 5.0 & 1.3 \\
\hline \multicolumn{3}{|l|}{ Manager Group } \\
\hline \multicolumn{3}{|l|}{ SES Changes } \\
\hline 1. Future outlook* & $3.6(\mathrm{Mdn}=4)$ & 1.2 \\
\hline 2. Shifting knowledge demands & 4.4 & 1.2 \\
\hline \multicolumn{3}{|l|}{ SES Complexity } \\
\hline 1. Unpredictable environmental changes & 4.9 & 1.1 \\
\hline 2. Unpredictable policies & 4.2 & 1.2 \\
\hline
\end{tabular}


Appendix 3: Content analysis codebook.

Sub-codes that have their own sub-codes are noted in italic typeface, and the definition provides details on points of distinction for further granularity

\begin{tabular}{|c|c|c|}
\hline $\begin{array}{l}\text { Code and total code } \\
\text { frequency }\end{array}$ & Sub-code & Definition \\
\hline \multirow{2}{*}{$\begin{array}{l}\text { Struggling cash } \\
\text { economy }\end{array}$} & Lack of wage employment & Concerns raised regarding wage employment opportunities. \\
\hline & Single-resource economy & Heavy reliance on a single industrial sector for revenue, lack of development leading to unsustainable economies \\
\hline High cost of living & ------- & Energy, housing, transportation costs due to isolated geographic location \\
\hline Risks to Culture & -------- & Eroding traditions and loss of Alaska Native languages \\
\hline $\begin{array}{l}\text { Ineffective decision } \\
\text { making }\end{array}$ & $\begin{array}{l}\text { Divided local interests } \\
\text { Inclusion } \\
\text { Regulation } \\
\text { Cross-cultural issues }\end{array}$ & $\begin{array}{l}\text { Disagreements among local entities, and governments } \\
\text { Inclusion of local communities in higher-level decision-making } \\
\text { Regulatory issues such as effectiveness, or transparency of, policies concerning for example (i) subsistence, (ii) tribal } \\
\text { sovereignty. } \\
\text { Misunderstanding of local needs by outside decision makers }\end{array}$ \\
\hline \multirow{3}{*}{$\begin{array}{l}\text { Risks from industrial } \\
\text { development }\end{array}$} & Industrial accidents & Problems from negative externalities of industrial development; Industrial disaster as risk to sustainability \\
\hline & Offshore & Offshore oil development as a potential risk to sustainability \\
\hline & Increased marine traffic & Risks from increased marine traffic, dated regulations not up-to-date with opening of routes \\
\hline Education issues & 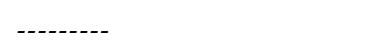 & Issues with the quality of the local school system, such as high turnover or lack of local teachers. \\
\hline Environmental issues & $\begin{array}{l}\text { Climate change impacts } \\
\text { Erosion, permafrost thaw - } \\
\text { without explicit reference to } \\
\text { climate change }\end{array}$ & $\begin{array}{l}\text { Respondent specifically mentions climate change impacts as a community concern. } \\
\text { Permafrost thaw, erosion and other land cover changes, but without explicit reference to climate change as the risk } \\
\text { source. }\end{array}$ \\
\hline \multirow[t]{2}{*}{$\begin{array}{l}\text { Community health } \\
\text { and health system } \\
\text { issues }\end{array}$} & $\begin{array}{l}\text { General } \\
\text { Services }\end{array}$ & $\begin{array}{l}\text { Unspecified concern for community health } \\
\text { Concern over access to, and quality of, care; the portfolio of services available such as health education, preventative } \\
\text { services, behavioral health, long-term care; and whether said services are culturally appropriate }\end{array}$ \\
\hline & $\begin{array}{l}\text { Substance abuse } \\
\text { Suicide }\end{array}$ & $\begin{array}{l}\text { Concern over rates of substance abuse in communities } \\
\text { Concern over suicide rates in communities }\end{array}$ \\
\hline Risks to subsistence & ------- & Concern about the health of subsistence economy: access to resources, transmission of traditional knowledge \\
\hline Demographic changes & ------ & Concern over aspects of in- or outmigration impacting the cultural pillars of communities \\
\hline
\end{tabular}

